\title{
PENGARUH KONTEN VLOG DALAM YOUTUBE TERHADAP PEMBENTUKAN SIKAP SOSIAL MAHASISWA ILMU KOMUNIKASI FISIP UNIVERSITAS ISLAM KALIMANTAN
}

\author{
Jacky Maulana \\ Universitas Islam Kalimantan MAB
}

\begin{abstract}
ABSTRAK
Youtube bisa pengaruhi perilaku seseorang, contoh beberapa hal seperti bunuh diri yang dilakukan dengan live streaming. Konten youtube memiliki dampak negatif dan dampak positif. Oleh karena itu, penting menurut saya untuk melihat bagaimana tanggapan mahasiswa tentang kebiasaan mereka menonton youtube, dengan perilaku sosial mereka yang cenderung acuh kepada perilaku seseorang di rumah, tempat kerja dan di kampus. Metode penelitian menggunakan pendekatan kuantitatif dengan jenis penelitian deskriptif kuantitatif. Data dikumpulkan dengan kuesioner kepada 30 orang respoden. Sample ditentukan dengan menggunakan teknik Non Probability Sampling dalam bentuk Purposive Sampling. Analisis data menggunakan korelasi pearson. Hasil penelitian menunjukkan bahwa tidak terdapat pengaruh keseringan menonton konten youtube dengan pembentukan sikap sosial mahasiswa Ilmu Komunikasi Universitas Islam Kalimantan. Hasil analisis pembentukan sikap sosial mahasiswa diperoleh 4 kategori sikap yaitu Sangat Baik (2,3\%), Baik (40,0\%), Cukup Baik $(20,0 \%)$ dan Kurang Baik terdapat (16,7\%). Dari hasil uji hipotesis mengenai pembentukan sikap sosial mahasiswa, diperoleh nilai Chi Square hitung X2 =3,867, nilai ini kemudian dibandingkan dengan nilai X2 tabel dengan taraf signifikan $0,05(5 \%)$ pada df 3 yaitu 7,815. Karena X2 hitung 3,867 < X2 tabel 7,815, maka hipotesis Ho diterima. Dengan demikian dapat disimpulkan bahwa pembentukan sikap sosial mahasiswa tersebar disemua tingkatan kategori sikap.
\end{abstract}

Kata Kunci: Vlog;Youtube;Pembentukan Sikap

\section{PENDAHULUAN}

Awal internet adalah jaringan komputer yang dibentuk tahun 1969 oleh Departemen Pertahanan Amerika, melalui proyek lembaga $A R P A$ yang mengembangkan jaringan yang dinamakan ARPANET (Advanced Research Project Agency Network). Tujuan awal dibangunnya Internet (Proyek Internet) adalah untuk keperluan militer. Pada masa tersebut Departemen Pertahanan Amerikat membuat sistem jaringan komputer yang tersebar dengan menghubungkan komputer di daerah penting (vital) untuk mengatasi masalah bila suatu saat terjadi serangan nuklir dan digunakan untuk menghindari terjadinya informasi terpusat, karena jika semua informasi dijadikan terpusat akan mudah dihancurkan bila terjadi perang.

Tetapi pada era sekarang ini perkembangan internet sudah sangat maju karena dapat memasuki segala aspek kehidupan manusia baik dalam bentuk entertainment dan infotainment dengan segala bentuk aplikasi - aplikasi atau website yang menyertainya. Perkembangan internet sekarang sudah dianggap bagian dari Teknologi Infomasi Komunikasi yang wajib dikuasai oleh masyarakat disebuah negara. Perkemangan internet mempunyai pengaruh positif terhadap perkembangan teknologi komunikasi.

Sekarang tidak ada lagi pembatasan perkembangan teknologi semakin berkembang salah satu perkembangan teknologi adalah banyaknya aplikasi - aplikasi yang behubungan dengan komunikasi ada aplikasi sosial media ada aplikasi informasi. Contoh aplikasi informasi : CNN, Babe, dan IDNtimes. Contoh aplikasi sosial media : WhatsApp, Twitter, Facebook, Instagram dan Youtube termasuk dari salah satunya.

Youtube adalah sebuah situs web video sharing (berbagai video) populer yang didirikan pada Februari 2005. Para pengguna dapat memuat, menonton dan berbagi klip video secara gratis. Umumnya video - video di YouTube adalah klip musik (video klip), film, TV, serta video buatan para penggunanya sendiri. Saat ini Youtube menjadi situs online video provider paling dominan di Amerika serikat, bahkan mungkin dunia, dengan menguasai 43 persen pasar. Diperkirakan 20 jam durasi video di upload ke Youtube setiap menitnya dengan 6 miliar views per hari.

Di Indonesia sendiri, internet baru mulai dikenal sekitar tahun 1990-an. Saat itu jaringan internet di Indonesia lebih dikenal dengan nama paguyuban network. Di saat tahun 1990-an tersebut, pengguna internet di Indonesia tidak sampai berjumlah ratusan apalagi ribuan seperti saat ini.

Sehubungan dengan itu penulis ingin mengetahui pengaruh konten vlog dalam Youtube terhadap pembentukan sikap Mahasiswa Ilmu Komunikasi Fakultas Ilmu Sosial dan Ilmu Politik Universitas Islam Kalimantan atau dengan kata lain 
apakah isi konten tersebut akan menjadi acuan mahasiswa dalam dan berperilaku dan bertindak dikehidupan bermasyarakat. Oleh karena iu peneliti menetapkan judul Pengaruh Konten Vlog Dalam Youtube Terhadap Pembentukan Sikap Mahasiswa Ilmu Komunikasi Fakultas Ilmu Sosial dan Ilmu Politik Universitas Islam

\section{Kalimantan}

\section{KERANGKA TEORI}

\section{Vlog}

Video Blog (Vlog) adalah sebuah video yang mempunyai tema tertentu yang dikemas dalam konsep dokumentasi jurnalistik dan dimuat dalam sebuah website. Biasanya video vlog berisi tentang ketertarikan, opini maupun pikiran, hampir mirip dengan tayangan televisi, walaupun dalam proses pembuatannya tidak serumit pembuatan tayangan televisi.

\section{Konten}

Konten adalah informasi yang tersedia melalui media atau produk elektronik. Penyampaian konten dapat dilakukan melalui berbagai medium baik secara langsung maupun tidak langsung seperti internet, televisi, CD audio, bahkan sekarang sudah melalui handphone.

\section{Pembentukan Sikap}

Menurut Bimo Walgito (2003:133), sikap tidak dibawa sejak dilahirkan, tetapi dibentuk sepanjang perkembangan individu yang bersangkutan. Sikap pada diri seseorang akan dipengaruhi oleh faktor internal, yaitu faktor fisiologis dan psikologis, serta faktor eksternal. Faktor eksternal dapat berwujud situasi yang dihadapi oleh individu, norma-norma yang ada dalam masyarakat, faktor penghambat dan faktor pendorong yang ada dalam masyarakat. Semua ini akan berpengaruh pada sikap yang ada pada diri seseorang.

\section{Sikap Sosial}

Sikap mulai menjadi fokus pembahasan dalam ilmu sosial, Syamsudin (1997: 74) mengemukakan bahwa sikap sosial dapat terlihat dari tujuh dimensi yang meliputi persahabatan, kepemimpinan, sikap keterbukaan, inisiatif sosial, partisipasi dalam kegiatan kelompok, tanggung jawab dalam tugas kelompok dan toleransi terhadap teman. Sedangkan menurut Loree dalam Syamsudin (1997: 74) sikap sosial adalah proses individu melatih kepekaankepekaan terhadap rangsangan - rangsangan terutama terhadap tuntutnan-tuntunan pokok

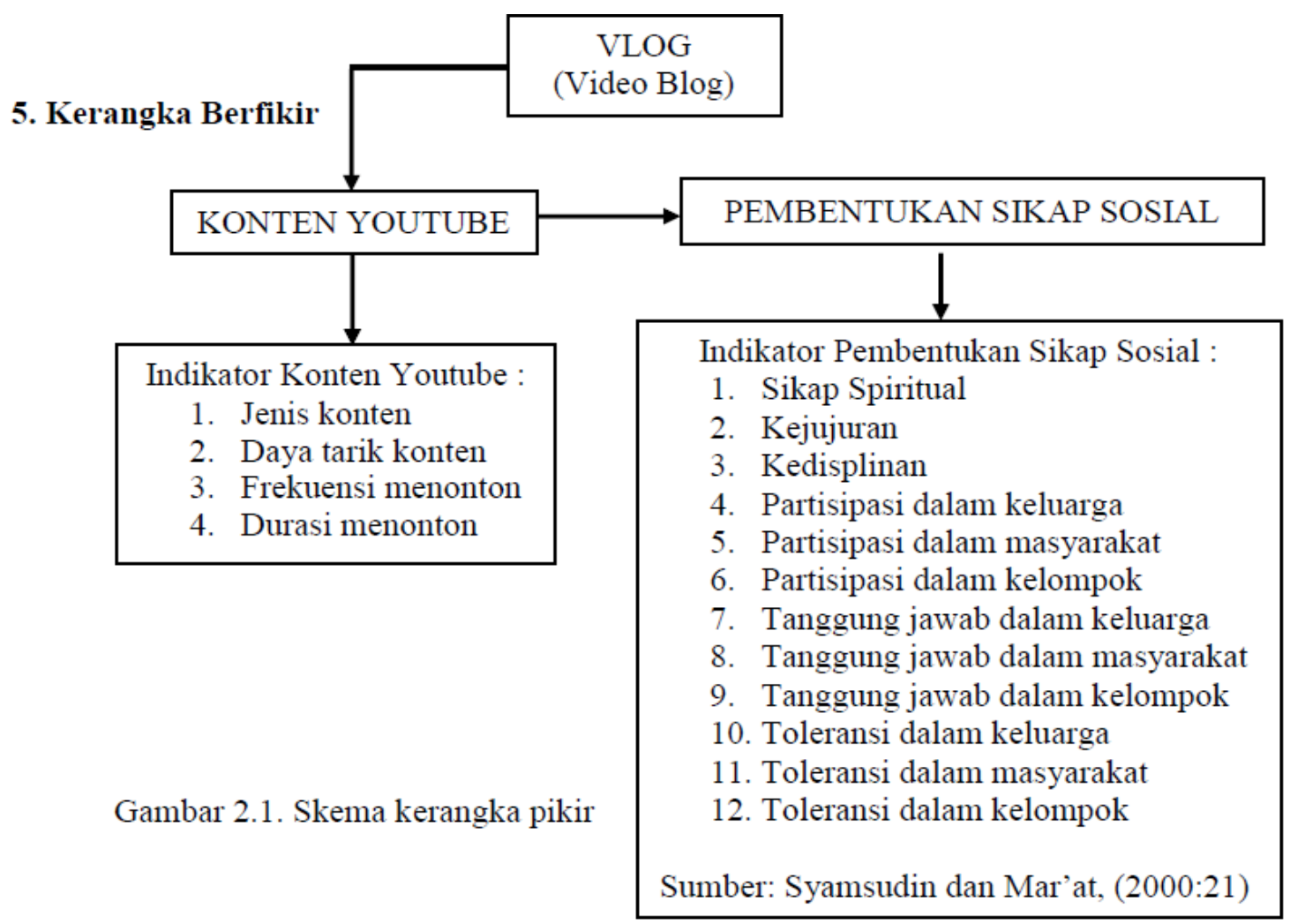




\section{Hipotesis}

Berdasarkan kerangka berpikir di atas, maka dapat ditarik rumusan atau dugaan sementara yang diambil sebagai hipotesis, yaitu:

Ho = Pembentukan sikap sosial mahasiswa tersebar disemua tingkatan kategori sikap.

$\mathrm{H} 1=$ Pembentukan sikap sosial mahasiswa tidak tersebar disemua tingkatan kategori sikap.

\section{METODE PENELITIAN}

1. Pendekatan Penelitian

Pendekatan ini bermula dari suatu kerangka teori, gagasan para ahli, maupun pemahaman peneliti berdasarkan pengalamannya, pendekatan penelitian yang banyak dituntut menguakan angka, mulai dari pengumpulan data, penafsiran terhadap data tersebut, serta penampilan hasilnya kemudian dikembangkan menjadi permasalahan permasalahan beserta pemecahannya yang diajukan untuk memperoleh pembenaran (verifikasi) atau penilaian dalam bentuk dukungan data empiris di lapangan. Penelitian ini menggunakan pendekatan kuantitatif dalam menganalisis pengaruh konten Vlog dalam Youtube terhadap pembentukan sikap sosial Mahasiswa Ilmu Komunikasi Fakultas Ilmu Sosial dan Ilmu Politik Universitas Islam Kalimantan.

\section{Tipe Penilitian}

Penelitian ini menggunakan tipe deskriptif kuantitatif yaitu menjelaskan atau menguraikan analisis dan kesimpulan berdasarkan data - data yang diperoleh di lapangan.

3. Lokasi Penelitian

Penelitian ini adalah penelitian lapangan yang berlokasi di Universitas Islam Kalimantan Fakultas Ilmu Sosial dan Ilmu Politik Prodi Ilmu Komunikasi di kota Banjarmasin yang terletak di Jalan Adhyaksa No. 02 Kayu Tangi Banjarmasin 70123 Tel. (0511) 3303876.

4. Populasi

Populasi adalah suatu kelompok yang terdiri dari objek atau subjek yang mempunyai kualitas dan karakteristik tertentu yang ditetapkan oleh peneliti untuk dipelajari dan kemudian ditarik kesimpulan (Sugiyono, 2010 : 117). Populasi pada penelitian ini adalah mahasiswa Fakultas Ilmu Sosial dan Ilmu Politik jurusan Ilmu Komuniksai Universitas Islam Kalimantan tahun 2019, berjumlah 282 mahasiswa.

\section{Sampel}

Sampel yang digunakan berjumlah 30 orang hal ini berdasarkan teknik pengambilan sampel menurut Gay dan Dhil (1992 : 163 ) bahwa bila sampel korelasional maka jumlah sample minimal berjumlah 30 orang.

6. Teknik Pengumpulan Data

Data yang dikumpulkan melalui teknik data primier dan data sekunder, data primer diperoleh langsung dilokasi penelitian dalam bentuk pertanyaan terbuka dan tertutup sedangkan data sekunder data yang diperoleh dari dokumen - dokumen yang terkait.

7. Definisi Operasional Variabel Penelitian

Definisi operasional adalah suatu definisi mengenai variabel yang dirumuskan berdasarkan karakteristik-karakterisik variabel tersebut yang dapat diamati (Azwar, 2007:74). Adapun definisi operasional dari variabel-variabel yang ada pada penelitian ini sebagai berikut :

A. Variabel Youtube

- Indikator Variabel Youtube :

1. Jenis konten

2. Daya tarik konten

3. Frekuensi menonton

4. Durasi menonton

B. Variabel Pembentukan Sikap

- Indikator Variabel Pembentukan Sikap Sosial:

1. Sikap Spiritual

2. Kejujuran

3. Kedisplinan

4. Partisipasi dalam keluarga

5. Partisipasi dalam masyarakat

6. Partisipasi dalam kelompok

7. Tanggung jawab dalam keluarga

8. Tanggung jawab dalam masyarakat

9. Tanggung jawab dalam kelompok

10. Toleransi dalam keluarga

11. Toleransi dalam masyarakat

12. Toleransi dalam kelompok

\section{Teknik analisis data}

Untuk melihat pengaruh konten vlog dalam Youtube terhadap pembentukan sikap sosial Mahasiswa Ilmu Komunikasi Fakultas Ilmu Sosial dan Ilmu Politik Universitas Islam Kalimantan data univariate menggunakan tabulasi sederhana dan Chi Square Goodness of Fit.

\section{HASIL PENELITIAN DAN PEMBAHASAN}

1. Konten Youtube

Tabel 4.1 Konten Youtube Yang Disukai 


\begin{tabular}{ccc}
\hline $\begin{array}{c}\text { Konten } \\
\text { Youtube } \\
\text { Yang Disukai }\end{array}$ & F & $\%$ \\
\hline Vlog & 1 & 3.3 \\
Film Pendek & 3 & 10.0 \\
Cover Lagu & 9 & 30.0 \\
Komedi & 3 & 10.0 \\
Live Video & 3 & 10.0 \\
Unboxing & 1 & 3.3 \\
Tutorial & 5 & 16.7 \\
Review & 2 & 6.7 \\
Games & 1 & 3.3 \\
Prank & 2 & 6.7 \\
\hline Total & 30 & 100.0
\end{tabular}

\begin{tabular}{ccc}
$>6$ Kali & 7 & 23.3 \\
\hline Total & 30 & 100.0 \\
\hline
\end{tabular}

Sumber: Data Primer 2019

Pada tabel diatas dilihat frekuensi menonton paling banyak 3 - 4 kali yaitu 12 orang $(40,0 \%)$, sedangkan paling sedikit frekuensi menonton Youtube 5-6 kali yaitu 5 orang $(16,7 \%)$, frekuensi yang menonton youtube 1 - 2 kali yaitu 6 orang $(20,0 \%)$, dan frekuensi yang menonton youtube $>6$ kali $(23,3 \%)$.

Tabel 4.4 Durasi Menonton Youtube

\begin{tabular}{ccc}
\hline $\begin{array}{c}\text { Durasi } \\
\text { Menonton } \\
\text { Youtube }\end{array}$ & F & $\%$ \\
\hline $5-10$ Menit & 4 & 13.3 \\
$11-15$ Menit & 4 & 13.3 \\
$16-20$ Menit & 7 & 23.3 \\
$>20$ Menit & 15 & 50.0 \\
\hline Total & 30 & 100.0 \\
\hline Sumber: Data Primer 2019 &
\end{tabular}

Tabel 4.2 Daya Tarik Konten Youtube

\begin{tabular}{|c|c|c|}
\hline $\begin{array}{c}\text { Daya Tarik } \\
\text { Konten Youtube }\end{array}$ & $\mathrm{F}$ & $\%$ \\
\hline Konten Menarik & 15 & 50.0 \\
\hline $\begin{array}{l}\text { Isi Konten Video } \\
\text { Mudah }\end{array}$ & 9 & 30.0 \\
\hline $\begin{array}{l}\text { Dimengerti } \\
\text { Kemampuan } \\
\text { Komunikasi } \\
\text { Vlogger }\end{array}$ & 6 & 20.0 \\
\hline Total & 30 & 100.0 \\
\hline
\end{tabular}

Pada tabel diatas dilihat durasi menonton Youtube paling banyak > 20 menit yaitu 15 orang $(50,0 \%)$, sedangkan paling sedikit durasi menonton Youtube 5 - 10 dan 10 - 15 menit yaitu 4 orang $(13,3 \%)$, durasi yang menonton youtube $16-20$ menit yaitu 7 orang $(23,3 \%)$.

2. Pembentukan Sikap Sosial Tabel 4.5 Tingkat Kejujuran

Sumber: Data Primer 2019

Pada tabel diatas dilihat daya tarik konten Youtube paling banyak yaitu konten menarik 15 orang $(50,0 \%)$, sedangkan paling sedikit daya tarik konten Youtube yaitu kemampuan komunikasi vlogger yang baik 6 orang $(20,0 \%)$.

Tabel 4.3 Frekuensi Menonton Youtube

\begin{tabular}{ccc}
\hline $\begin{array}{c}\text { Frekuensi } \\
\text { Menonton } \\
\text { Youtube }\end{array}$ & F & $\%$ \\
\hline $1-2$ Kali & 6 & 20.0 \\
$3-4$ Kali & 12 & 40.0 \\
$5-6$ Kali & 5 & 16.7
\end{tabular}

\begin{tabular}{ccc}
\hline $\begin{array}{c}\text { Tingkat } \\
\text { Kejujuran }\end{array}$ & F & $\%$ \\
\hline Kurang Baik & 6 & 20.0 \\
Cukup Baik & 16 & 53.3 \\
Baik & 8 & 26.7 \\
\hline Total & 30 & 100.0 \\
\hline Sumber: Data Primer 2019 &
\end{tabular}

Tingkat Kejujuran adalah suatu kesesuaian sikap antara perkataan dan perbuatan yang sebenarnya, dan apa yang diucapkan memang itulah yang sesungguhnya dan apa yang di perbuat itulah yang sebenarnya. Pada tabel diatas dapat dilihat pendapat responden tentang tingkat kejujuran 16 orang $(53,3 \%)$ berpendapat dalam kategori Cukup Baik, sedangkan Baik 8 orang $(26,7 \%)$, dan 6 
orang $(20,0 \%)$ yang berpendapat Kurang Baik.

Tabel 4.6 Tingkat Partisipasi Dalam Keluarga

\begin{tabular}{ccc}
\hline $\begin{array}{c}\text { Tingkat } \\
\text { Partisipasi } \\
\text { Dalam } \\
\text { Keluarga }\end{array}$ & F & $\%$ \\
\hline Kurang Baik & 17 & 23.3 \\
Cukup Baik & 17 & 56.7 \\
Baik & 6 & 20.0 \\
\hline Total & 30 & 100.0 \\
\hline
\end{tabular}

Sumber: Data Primer 2019

Pengertian partisipasi menurut Keith Davis, pengertian partisipasi adalah keterlibatan mental atau pikiran atau moral atau perasaan di dalam situasi kelompok yang mendorongnya untuk memberikan sumbangan kepada kelompok dalam usaha mencapai tujuan serta turut bertanggung jawab terhadap usaha yang bersangkutan. Kondisi keluarga yang rukun dan bahagia ini merupakan wujud partisipasi dalam menciptakan ketenteraman dan kedamaian keluarga. Upaya menjaga ketentraman dan kedamaian keluarga ini sudah merupakan bentuk partisipasi. Pada tabel diatas dapat dilihat pendapat responden tentang tingkat partisipasi dalam keluarga 17 orang $(56,7 \%)$ berpendapat dalam kategori Cukup Baik, yang berpendapat Baik 6 orang $(20,0 \%)$, yang berpendapat Kurang Baik 7 orang $(23,3 \%)$.

Tabel 4.7 Tingkat Tanggung Jawab Dalam Masyarakat

\begin{tabular}{ccc}
\hline $\begin{array}{c}\text { Tingkat } \\
\text { Tanggung } \\
\text { Jawab Dalam } \\
\text { Masyarakat }\end{array}$ & $\mathrm{F}$ & $\%$ \\
\hline Kurang Baik & 5 & 16.7 \\
Cukup Baik & 12 & 40.0 \\
Baik & 12 & 40.0 \\
Sangat Baik & 1 & 3.3 \\
\hline Total & 30 & 100.0 \\
\hline
\end{tabular}

Sumber: Data Primer 2019

Pada hakekatnya manusia tidak bisa hidup tanpa bantuan orang lain karena manusia kedudukannya sebagai makhluk sosial yang membutuhkan manusia lain maka kita harus berkomunikasi dengan manusia lain tersebut. Berinteraksi didalam suatu kehidupan masyarakat sangat dibutuhkan karena itu bisa membuat kita saling mengenal satu dengan yang lainnya. Pada tabel diatas dapat dilihat pendapat responden tentang tingkat tanggung jawab dalam masyarakat 12 orang $(403,3 \%)$ berpendapat dalam kategori Cukup Baik dan Baik yang berpendapat Kurang Baik 5 orang $(16,7 \%)$. dan 1 orang $(3,3 \%)$ yang berpendapat Sangat Baik.

Tabel 4.8 Tingkat Toleransi Dalam Kelompok

\begin{tabular}{ccc}
$\begin{array}{c}\text { Tingkat } \\
\text { Toleransi } \\
\text { Dalam } \\
\text { Kelompok }\end{array}$ & F & $\%$ \\
Kurang Baik & 6 & 20.0 \\
Cukup Baik & 13 & 43.3 \\
Baik & 11 & 36.7 \\
\hline Total & 30 & 100.0 \\
\hline
\end{tabular}

Sumber: Data Primer 2019

Tingkat toleransi dalam kelompok adalah sikap toleransi bukan berarti membenarkan semua pandangan yang dibiarkan itu, tetapi mengakui kebebasan serta hak-hak asasi para penganutnya. Toleransi adalah suatu sikap saling menghargai kelompok - kelompok atau antar individu dalam masyarakat.

\section{PENUTUP}

\section{Kesimpulan}

Dari penelitian yang telah dilakukan mengenai pengaruh konten vlog dalam Youtube terhadap pembentukan sikap sosial Mahasiswa Ilmu Komunikasi Fakultas Ilmu Sosial dan Ilmu Politik Universitas Islam Kalimantan, maka dapat disimpulkan sebagai berikut:

Bahwa ternyata pengaruhnya itu tidak terlihat karena hasil analisis tentang pengaruh dalam pembentukan sikap sosial mahasiswa Ilmu Komunikasi Universitas Islam Kalimantan diperoleh hasil pembentukan sikap Kurang Baik terdapat 5 orang (16,7\%), Cukup Baik 6 orang $(20,0 \%)$, Sangat Baik 7 orang $(2,3 \%)$ dan Baik 12 orang $(40,0 \%)$

Dari uji hipotesis diperoleh nilai Chi Square hitung $\mathrm{X} 2=3,867$, nilai ini kemudian dibandingkan dengan nilai X2 tabel dengan taraf signifikan $0,05(5 \%)$ pada df 3 yaitu 7,815. Karena X2 hitung 3,867 $<$ X2 tabel 
7,815, maka hipotesis Ho diterima. Dengan demikian dapat disimpulkan bahwa pembentukan sikap sosial mahasiswa tersebar disemua tingkatan kategori sikap.

\section{Saran}

Berdasarkan hasil penelitian tentang pengaruh konten vlog dalam Youtube terhadap pembentukan sikap sosial Mahasiswa Ilmu Komunikasi Fakultas Ilmu Sosial dan Ilmu Politik Universitas Islam Kalimantan, maka dapat dikemukakan saran sebagai berikut : Mengurangi nonton frekuensi Youtube dan durasi karena itu dapat mempengaruhi sikap sosial, dengan mengurangi frekuensi dan durasi menonton Youtube diharapkan sikap sosial mahasiswa terhadapat keluarga, masyarakat dan kelompok nya akan menjadi sangat baik.

\section{DAFTAR PUSTAKA}

Ahmadi. (2003). Psikologi Umum. Jakarta: Rineka Cipta

Aisyah, Siti. 2017. Skripsi : Video Blog Sebagai Media Representasi Diri Vlogger di Kota Makassar. Makassar

Akbar, A. 2018. Efektifitas Youtube Sebagai Media Penyebaran Informasi. Skripsi.

Alex Sobur. (2003). Psikologi Umum. Bandung: Pustaka Setia.

Asep Saeful Muhtadi, 2015, Metode Penelitian Komunikasi Penelitian

Azwar, Saifuddin. 2007. Metode Penelitian. Pustaka Pelajar: Yogyakarta.

Bandura, A,1989. Self-efficacy mechanism in physiological activation

Bimo Walgito. (2003). Psikologi Sosial (Suatu Pengantar). Yogyakarta: ANDI

Casram. (2016). Membangun Sikap Toleransi Beragama Dalam Masyarakat Plural. Jurnal Ilmiah Agama dan Sosial Budaya, 1, 188-197.

Clarkson, Stephanie. 2015. Vlog It!. United Kingdom: Scholastic

Crutchfield, R.S. (1948). Theory and Problems of Social Psychology. New York: McGrawHill.

David, Eribka Ruthellia. dkk. 2017. 'Pengaruh Konten Vlog dalam Youtube terhadap Pembentukan Sikap Mahasiswa Ilmu Komunikasi Fakultas Ilmu Sosial dan Politik Universitas Sam Ratulangi. Vol VI No.1: 8-9

Dian Kurniawati. 2005. faktor-faktor yang mempengaruhi pendidikan anak di Desa Kabongan Lor dan Desa Gegunung Wetan Kecamatan Rembang Kabupaten Rembang. Surakarta: Skripsi Sarjana Fakultas Geografi UM
Gay, L.R. dan Diehl, P.L. (1992), Research Methods for Business and. Management, MacMillan Publishing Company, New York health-promoting behavior. In J. Madden, S. Matthysse, \& J. Barchas (Eds.), Adaptation, learning and affect (pp. 1169-1188). New York: Raven.

Goleman, Daniel. 2007.Kecerdasan

Emosional.Jakarta: PT. Gramedia PustakaUtama.

Helianthusonfri, Jefferly. (2016). YouTube Marketing. Jakarta: PT Elex Media Komputindo.Kencana.

Katz, Daniel \& Kahn, Robert L. 1970. The Social Psychology of Organizations.Dalam Becker \& Neuhauser The Efficient Organizations. New York. Elsevier.

Kindarto, Asdani. 2008, Belajar Sendiri Youtube (Menjadi Mahir Tanpa Guru), Jakarta: PT Elexmedia Komputindo. Kuantitatif:Teori dan Aplikasi, Bandung: Pustaka Setia.

Kurniawati, Desy. 2005.Pengaruh Budaya Organisasi, Kepemimpinan Dan MotivasiKerja Terhadap Kepuasan Kerja Karyawan Di Restaurant Sari UtamaJember. Skripsi. Fakultas Ekonomi Universitas Kristen Petra Surabaya.

Maman Suryaman. 2015. Penggunaan YouTube Sebagai Media Pengajaran

Manurung, Anggia Dewi Fransiska. 2010. Motivasi Mahasiswa Komunikasi Metode Penelitian. Universitas Indonesia. Jakarta.

Nasrullah, Rulli. 2014. Teori dan Riset Media Siber (Cyebermedia). Jakarta:

Notoatmodjo, S .2005. Promosi Kesehatan teori dan aplikasinya.Jakarta: Rineka Cipta.

Santoso, Edi,Mike Setiansih. 2010.Teori Komunikasi.yogyakarta : Graham Ilmu

Sarana Menyebarluaskan Berita, Skripsi (Universitas Sultan Ageng Tirtayasa, Fakultas Ilmu Sosial dan Ilmu Politik, 2014). diakses tanggal 25 Februari 2019

Sarwono, Sarlito W. 2009. Pengantar Psikologi Umum.Depok: Rajawali Pers.

Sevilla, C.G. Jesus, A.O. Twila, G.P. Bella, P.R. Gabriel, G.U. 1993. Pengantar

Slameto. 2003. Belajar dan Faktor-faktor yang Mempengaruhinya. Jakarta: Rineka

Cipta.

Soekresno.2001.Manajemen Food \& Baverage Service

Hotel.Jakarta:GramediaSuharsimi.Arikunt o.2006.Dasar-Dasar EvaluasiPendidikan. Jakarta: Bumi Aksara

Sugiyono. 2010.Metode Penelitian 
MUTAKALLIMIN; Jurnal Ilmu Komunikasi

Vol 4 No 1 Mei 2021

Kuantitatif,kualitatif dan RnD.Bandung :Alfabeta

Suharsimi. 2010. Prosedur Penelitian Suatu pendekatan Praktek. Jakarta: Rineka Cipta

Supranto, J. 2003. Metode Riset Aplikasi Dalam

Pemasaran.

Edisi

RevisiKetujuh.Yogyakarta: Rineka Cipta. Spector, Paul. E. 2000.Industrial and

Organizational Psychology: Research andPractice-2ndEdition. New York: John Wiley \& Sons

Syamsudin, Abin. 1997. Perilaku Sosial Pada

Siswa yang Memiliki Prestasi

Akademik Rendah Di Sekolah Dasar.

Widayatun. 2009. Ilmu Perilaku. Jakarta : Info Medika

https://kumparan.com/jofie-yordan/google-durasitonton-dan-jumlah-kontenyoutube-Indonesiatumbuh-pesat (diakses tanggal 20 Juli 2019)

https://www.idntimes.com/life/inspiration/faidahrahim/8-ide-konten-youtube-buat-kamu-yang-gaksuka-tampil-di-depan-kamera-c1c2\# (diakses tanggal 24 Juli 2019)

https://www.gramedia.com/blog/jenis-kontenvideo-paling-populer-di-youtube/\#gref (diakses tanggal 27 Juli 2019) 